\title{
Logic and Ontology in Hegel's Theory of Predication
}

\author{
Kevin J. Harrelson
}

\begin{abstract}
In this paper I sketch some arguments that underlie Hegel's chapter on judgment, and I attempt to place them within a broad tradition in the history of logic. Focusing on his analysis of simple predicative assertions or 'positive judgments', I first argue that Hegel supplies an instructive alternative to the classical technique of existential quantification. The main advantage of his theory lies in his treatment of the ontological implications of judgments, implications that are inadequately captured by quantification. The second concern of this paper is the manner in which Hegel makes logic not only dependent on ontology generally, but also variant in regard to domains of objects. In other words, he offers a domain-specific logical theory, according to which the form of judgment or inference is specific to the subject of judgment. My third concern lies with the metaphilosophical consequences of this theory, and this includes some more familiar Hegelian themes. It is well known that Hegel frequently questioned the adequacy of the sentential form for expressing higher order truths. My reading of his theory of predication explains and contextualizes this tendency by demystifying notions like the so-called speculative proposition.
\end{abstract}

In this paper I sketch some arguments that underlie the chapter on judgment from Hegel's Science of Logic, and I attempt to place them within a broad tradition in the history of logic. ${ }^{1}$ Focusing on his analysis of simple predicative assertions or 'positive judgments', I first argue that Hegel supplies an instructive alternative to the classical technique of existential quantification. ${ }^{2}$ The main advantage of his theory lies in his treatment of the ontological implications of judgments, implications that are inadequately captured by quantification. The second concern of this paper is the manner in which Hegel makes logic not only dependent on ontology generally, but also variant in regard to domains of objects. In other words, he offers a domain-specific logical theory, according to which the form of judgment or inference is specific to the subject of judgment. My third concern lies with the metaphilosophical consequences of this theory, and this includes some more familiar Hegelian themes. It is well known that Hegel frequently questioned the adequacy of the sentential form for expressing higher-order truths. ${ }^{3} \mathrm{My}$ reading of his theory of predication explains and contextualizes this tendency by demystifying notions like the so-called speculative proposition. Hegel's theory, on my account, permits a range of formal distinctions among judgments. Metaphysical assertions such as 'God is one' form just one end of the spectrum, with simple predications such as 'the rose is red' at the other extreme.

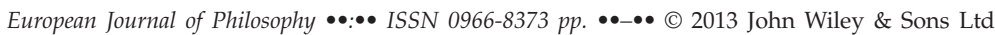


These discussions should recast the common accusation that Hegel conflates logic with metaphysics, largely by highlighting the inevitable dependence of the use of logic on prior assumptions. ${ }^{4}$ The charge in question is an old one, and the perception that Hegel treated logic as a branch of metaphysics is a primary reason why he has been regarded as having little or nothing to teach us about the former. My contention is that Hegel did not mistake logic for a branch of metaphysics, but rather he confronted some inevitable intersections between logic and ontology. The central element of this analysis is his insistence upon formal differences among domains of discourse. Most formal systems, by contrast, attempt only to reduce logic to a few connectives or rules of inference. The common assumption is that this should explain away any differences among discourses about diverse domains of object (e.g., mats, cats, gods, friendships, quarks, or rights). Hegelian logic is expansive rather than reductive, and so also ontologically sensitive. His theory of predication distinguishes rather than reduces the diverse manners of predicative judgment, and Hegel allows that what we judge can make a difference to the form of judgment. In order meaningfully to analyze a judgment, he argues, we need to know in advance what the identity conditions for the given objects are..$^{5}$

Many of the common worries about excessive metaphysics in Hegel dissolve, on my reading, if we view his various theories in light of his analysis of propositions. In this respect I propose my reading as an alternative to both metaphysical and non-metaphysical approaches to Hegel, one that does him textual justice while also highlighting aspects of his thought that are relevant to contemporary problems. ${ }^{6}$ The general question concerning metaphysical sentences has most often come to the fore-in Hegel as in more traditional thought-in the defense of the ontological argument. Hegel followed many so-called dogmatic metaphysicians by insisting that the conceptual content 'God' does not form the subject term in judgments in the same manner as do some other subjects, such as 'one hundred dollars'. ${ }^{7}$ The difference between Hegel and the dogmatists, however, lay in the fact that the former provides a general analysis of logical form, and so offers a context and attempted justification of differences like that between God and a sum of money. ${ }^{8}$ In a similar vein, attention to Hegel's theory of predication will enable us to offer plausible readings of many sections of his philosophy, including his philosophies of history and right. In this essay, however, I place little emphasis on such examples, since they can obscure as much as illustrate the general point about logical form.

\section{Propositional Logic and Propositional Ontology}

In this first section I deal with Hegel's conception of the subject matter of a portion of his Begriffslogik ('the logic of concepts'), or the third and final book of his Science of Logic. My intention is to place his theory within a broad tradition including Quine and Russell. In this section of his work, Hegel offers a set of

(C) 2013 John Wiley \& Sons Ltd 
theses about both the formal properties and the ontological implications of sentences. Questions about the ontology implied by logical form have exercised analytic philosophers as well as Hegel, although it is not always easy to compare results across traditions. In a very early essay, Quine expressed dismay about the fact that most philosophers concerned with propositional logic had neglected the relevant questions of ontology. ${ }^{9}$ Propositional logic, he insisted, leads inexorably to the problem of a corresponding ontology. Every theory of the proposition begs for an ontology, if only because every theory of anything does. ${ }^{10}$ The simplest candidate is the one that Russell proposed around 1903, which asserts a straightforward thesis: if truth is a characteristic of sentences, there must correspond to them some sentence-like objects. ${ }^{11}$ On this point, as on most, Hegel stands in stark opposition to Russell. Hegel rather famously questioned the capacity of sentences to express various orders of truth, including philosophical truth. The important introductory point is that while this thesis does not belong to logical theory in the narrow sense, it does belong to the ontology of propositional logic in Quine's sense.

Hegel's rejection of the sentence concludes a detailed analysis of sentential forms in which he distinguishes an array of ontological presuppositions that belong to the various types of sentence. ${ }^{12}$ His main thesis is that not all sentences require the same ontology, but rather diverse sentential forms contain diverse presuppositions. Not every sentence, for instance, is referential, and among referential sentences there are many varieties of reference. The simplest forms of judgment, the so-called 'positive judgments', presume that there are individual entities in which universal predicates inhere. Hegel expresses this assumption by claiming that 'the individual is universal', a second-order sentence that has been badly misunderstood by many of his most famous critics. ${ }^{13}$ The claim does not belong to general metaphysics, but rather to the ontology of elementary sentences. 'The individual is the universal' expresses the propositional ontology of a basic sentential form, and Hegel judges both the sentential form and the ontology to be inadequate to most meaningful discourse. More complex forms of judgment demand more nuanced ontologies, since most subjects of discourse are precisely not individual entities in which universal predicates inhere. ${ }^{14}$ Hegel thus offers not only a diverse ontology of logical forms, but also a thesis about their limits and application. One consequence of his position on which I will insist-one that is more instructive for us than it was for him-is that most subjects of discourse do not admit of analysis by a reductive propositional logic.

Hegel's contribution to propositional ontology has been misunderstood mainly due to a prevalent inference about the range and application of formal logics: the abstract nature of logic was supposed by many critics to guarantee its universal applicability, whereas Hegel argues that most linguistic forms apply only to very specific domains of discourse or species of object. I label the (relatively harmless) thesis in the premise of this inference 'domain-neutrality', which says that the content of logic is a matter distinct from any particular bit of cognition. The second, more contentious thesis is 'logical globalism', which says that a given logical criterion applies to any and every instance of

(C) 2013 John Wiley \& Sons Ltd 
knowledge ${ }^{15} \mathrm{~A}$ long tradition in logic, inspired by Kant but continued by many formal logicians, has assumed that global application follows from domainneutrality, an assumption which no longer appears indisputable. The law of noncontradiction, for instance, might be in some meaningful sense ontologically neutral, but whether it applies to all objects or discourses, including quantum objects, is a different question. Hegel's arguments, while of course not oriented toward this example, require us to keep in mind the distinction between the formality or neutrality of logic and its application (viz. globalism). The Begriffslogik opens with a polemic against Kant in which Hegel argues precisely that the formal character of logic does not imply that it has global application. ${ }^{16}$

Before discussing Hegel's direct arguments against Kant's thesis, I wish to illustrate and contextualize this worry about logical globalism. Kant's position, in a passage cited by Hegel and discussed below, is that any formal criterion of truth must be valid without regard for which objects are discussed. One consequence of this for logicians is that it should make little difference whether we are discussing, for example, roses or the Roman empire. Statements in botany or gardening, as well as in world history or quantum theory, would be analyzable by the same criteria. The claim that a given rose is red should have the same form as the more complex statements by Hegel about such matters as the historical birth of philosophy, such as (and I choose nearly at random) 'in Stoicism pure thinking first develops itself into totality. ${ }^{17}$ In order to analyze this last sentence, however, we need to specify both 'pure thinking' and 'stoicism' as plausible objects of historical discourse. For this Hegel can allow formal analysis while denying only logical globalism. More modern logics indeed provide a successful analysis of 'the rose is red' by techniques such as quantification $[(\exists x)$ Rx - Dx], but this does not imply that the statements about 'Greek philosophy' should be assessed in the same manner. This is the upshot, I argue in section 3, of Hegel's many distinctions among kinds of sentences: the fact that a certain type of sentence has certain formal properties does not imply that all sentences will have those properties.

The most influential among Hegel's early critics in logic emphasized these dual requirements of ontological neutrality and global application, and as a result they excluded Hegel's writings from the official understanding of that discipline. Trendelenburg, Zeller, and others sought to define logic as a formal discipline so that they could restore a proper relationship between philosophy and the special sciences. ${ }^{18}$ Ontological neutrality in logic was essential to defending the autonomy of the sciences, while global application encouraged a surveillance role for philosophy. It was only in neglecting these characteristics of logic, they argued, that Hegel drew such broad consequences from his theory. Hegel's refusal to treat logic as an enterprise distinct from the study of other entities gave him the wrong kind of relation between logic and the special areas of philosophy, and on his principles he could too easily combine the study of logical form with other branches of human inquiry. Exemplary texts are indeed easy to discover in which Hegel imposed burdensome juxtapositions of content. The Encyclopedia, for instance, introduces the concept of

(C) 2013 John Wiley \& Sons Ltd 
universality with a discussion of how this required the elimination of slavery as a human practice. ${ }^{19}$

This somewhat obscure back-history warrants mention because the later the rise of mathematical logics (curiously) both heightened the sense of Hegel's irrelevance and put into question the global applicability of formal logics. Henry Macran's rather meek attempt to revive Hegel's logic in 1911 met with a vigorous polemic by Russell in which the latter declared in plain terms that Hegel's theory was 'not about logic. ${ }^{20}$ In this newer context, however, the place of logic in relation to the special sciences was changed in a significant way: logic now possessed a local domain in the justification of arithmetic. ${ }^{21}$ While this role encouraged an ontologically neutral logic, it left open the question of application. To be sure, mathematical languages have often functioned as translations of natural language sentences, but this has not generally been accompanied with a justification of such use. ${ }^{22}$ By what right do mathematical logics apply to other domains of object, discourses, disciplines, etc.? What reasons do we have to expect that an arithmetical logic can formalize correct inference? Answers to these questions are very difficult to glean from even the best philosophers of logic, although Hegel is not without suggestions on the topic. ${ }^{23}$ He was of course ignorant of post-Fregean developments, but what he wrote about reductive explanations in traditional logic transfers rather well to this question. ${ }^{24}$ In particular, the employment of formal languages for purposes other than the justification of arithmetic supposes that quantification can serve as a complete theory of propositions, and it is here that Hegel's reflections again become relevant.

Whereas historical developments concerned the systematic consequences of neglecting formal logic, much of Hegel's own argumentation concerns only some conceptual difficulties of defining a merely formal inquiry, viz., in delimiting a science that is distinct from other areas of knowing, and yet applies equally to them all. Some of Hegel's arguments indeed attack the premise that logic concerns only form, but his best argument aims rather at the inference from formalism to global application. In the following I wish to emphasize the latter argument, while acknowledging that Hegel sometimes seems to attack formal analysis as such. The more successful argument concludes only that formal sciences require second-order justifications. In this Hegel does not reject or overlook the form-content distinction, but rather he draws some implications of various logical forms. I emphasize this point not only because it suits my purposes, but also because it better explains the actual analyses of sentential forms that appear in the chapter on judgment.

Hegel's argument requires that he reject the above-mentioned Kantian inference from formal abstraction to logical globalism. The inference in question, as he addresses it in the introductory section to the Begriffslogik, appears in one of Kant's early discussions of the form-content distinction. Hegel's citation from the Critique of Pure Reason (B 83-84) is rather free, and he follows Kant in relating the form-content distinction to the correspondence theory of truth $^{25}$ :

(C) 2013 John Wiley \& Sons Ltd 
What we seek ... is a secure and universal criterion of every cognition; it would have to be valid for every cognition without distinction in regard to its object; since we abstract from the content of each cognition (viz., its relation to its object), and since truth concerns precisely this content, it would be impossible and inappropriate to inquire into a sign of the truth of the content of the given cognition. ${ }^{25}$ (my translation and emphasis)

Hegel offers three counterarguments of variant success. The first two aim at the premise of ontological neutrality, and these leave Hegel open to the potential counter that he neglects Kant's distinction between formal and transcendental logic. ${ }^{26}$ The first argument begins with the claim that Kant's position mistakes its own criterion for truth: truth concerns the relationship of agreement between contents and concepts, not merely some content stripped of its own form. If we grant the logical formalist the separation of form and content, then neither side can be true. The form in that case, since it possesses no content, would be incapable of a correspondence to anything, whereas the content would be Begriffslos-a blind material. ${ }^{27}$ This argument suggests, perhaps somewhat in jest, that formal logics are empty.

Hegel's second argument concludes that logical forms must correspond to their own contents. He begins by asserting a pragmatic contrary to Kant's position: any expression of formalism is contradictory. Formalism says that we cannot look for truth in the form of judgments, precisely because truth is only a matter of the content. In doing so it always asserts the opposite of what it intends if it endeavors on any explanation at all. ${ }^{28}$ The (unstated) premise here is that in order to explain what is meant by 'form', one must lend some content to the concept of it. In that case, however, we are again not discussing mere form but rather a particular content. A more global version of this argument underlies the very long-standing scholarly conflict between epistemic and metaphysical interpretations of Kant, and it is at least plausible to deny the possibility of a formal science by means of this type of objection. ${ }^{29}$ To his credit, Hegel immediately foregoes further discussion of this problem, since he has no need to oppose Kant so strictly by showing that the idea (or expression) of a formal logic is contradictory.

Hegel does not need to declare a formal logic impossible, since the theory that he proposes is only an extension of formal analysis. His best argument against logical formalism shows that logical forms require metalogical justifications. ${ }^{30}$ This move blocks the inference from the domain-neutral aspect of logic to its global application, because it allows that diverse propositional forms require diverse ontologies. He appeals to the formalist's own definition of truth in terms of adequatio, according to which truth is supposed to be a characteristic of the content. Since even formal logic must have a content that corresponds to something, it is reasonable to ask whether logical forms are themselves true: 'the formal aspect must have its own content if it is to be a candidate for truth, and this content must be proportionate to its form; this is especially the case since the formal aspect of logic is pure form, and truth in logic is truth as such. ${ }^{31}$ Logical

(c) 2013 John Wiley \& Sons Ltd 
forms can be true only if they are adequate to their contents, where by 'content' Hegel refers to one or another of a set of ontological assumptions. The positive judgment, for instance, 'expresses the proposition that "the individual is the universal".'32 The statement 'the individual is the universal' is, to coin an awkward expression, the metalogical content for positive judgments of the form 's is $\mathrm{P}^{\prime}$. A complete account of that sentential form needs to show under what conditions the logical form corresponds to this content.

Unlike the globalist, then, Hegel provides a framework for asking whether the kinds of sentence that we use are adequate to the subject matters that we discuss: the so-called positive judgment is a valid form only for given individuals in which abstract predicates inhere. 'The individual is the universal' is thus no strange doctrine of Hegelian metaphysics but rather the initial and unexamined ontology of a certain sentential form. In other words, positive judgments ( $\mathrm{s}$ is P) assert that general predicates inhere in individual objects, and Hegel develops a metalogical theory to examine the adequacy of assumptions of this sort. The positive judgment 's is $\mathrm{P}^{\prime}$ predictably turns out to be inadequate for most very interesting forms of discourse, such as ethics, history, politics, metaphysics, etc. The reason for this is that the objects discussed in these cases (rights, justice, the Roman empire, the will of the people, etc.) are not individuals that contain predicates in the same manner that the rose contains redness.

\section{Hegel's Sentential Semantics}

In this section I review some of the early arguments of the chapter on judgment, insofar as they express a set of theses about the relationship of subject to predicate. In some contemporary circles this topic is labeled 'sentential semantics', and part of my aim is to attribute to Hegel a novel position on the relevant issues. Sentential semantics concerns how sentences acquire meaning by applying predicates to subjects, and theories on this topic typically divide into compositional and contextual accounts. ${ }^{33}$ According to compositional accounts, sentences are composed of distinct terms or sentential components-the subject is distinct from the predicate. According to contextual accounts, the terms or components of a sentence have meaning only in the context of that sentence. Hegel's position is novel in that he accepts important elements of each option. He holds that a sentence or proposition is only informative if it is comprised of distinct terms, but he argues that every sentential component requires a very broad contextual specification. The result of these two moves by Hegel is a hybrid theory of the sentence, and it leads to some significant criticisms of sentential form. Contrary to Russell's famous criticism, Hegel acknowledges that predication differs from identity. He begins with the premise that subjects and predicates are distinct elements, but he infers from this very point to a strong contextualism for sentences. In other words, Hegel takes the very distinction among sentential components to imply that sentences are not independent bearers of truth.

(C) 2013 John Wiley \& Sons Ltd 
In the so-called positive judgment, the predicate term is ascribed to a given individual subject. The shortcoming of logical globalism, again, is that this form is assumed to be adequate to all discourse, whereas on Hegel's account the relationships between subjects and predicates will differ. It will be useful to compare Hegel's domain-specific approach with an analysis of positive judgments according to standard, first-order predicate logics. Textbook logics translate sentences like 'the rose is red' into the following formalism: $(\exists x) \mathrm{Rx} \bullet \mathrm{Dx}$, where $\mathrm{R}$ stands for 'is a rose' and D stands for 'is red'. This quantificational reading of the positive judgment has the following characteristics:

(1) The subject and predicate terms are given as distinct items; being a rose is one thing, whereas being red is another.

(2) Existence is a logical characteristic that is taken as distinct from the remaining content of the sentence.

(3) Due to the use of the variable ' $x$ ', the subject of the sentence is distinguished from its identification as a rose.

The formal technique distinguishes predication from both identity and existence, an achievement much celebrated in the classical literature on predicate logic. ${ }^{34}$ The quantificational term asserts that some $\mathrm{x}$ exists, whereas the terms for both the subject and predicate stand outside the parentheses. The very grammar of our formalism thus says that existence and predication are distinct ideas, which is why many have associated Kant's famous criticism of the ontological argument with these chronologically later developments. ${ }^{35}$ Unlike in Kant's particular analysis, however, the formal technique does not commit the logician to a specific account of existence. The formalism in fact leaves the relationship between this logical characteristic and its ontological siblings (reality, actuality, objectivity, spatio-temporality, etc.) entirely unelaborated. Whether $\mathrm{x}$ is a fictional entity, an abstract entity, a spatiotemporal entity, a postulate of natural science, or a god is irrelevant to the formal structure of the sentence interpreted in this idiom. The logical characteristic 'existence' may belong to any of these-a point obscured not only in logic textbooks but also in much literature in the philosophy of logic. ${ }^{36}$ Identity, on the other hand, is excluded by the distinction between $\mathrm{R}$ and $\mathrm{D}$, which distinction is reflected both in the grammar that separates them by ' $\bullet$ ' as well as the use of two different letters. These separations suggest that the positive judgment does not present an instance of an identity statement ('the rose is the rose' or 'the rose in the vase is Sam's gift to me'), in the absence of some other statement that $\mathrm{R}=\mathrm{D}$. In our example, redness is indeed a different conceptual content than is rosiness.

In this analysis, however, 'predication' is only a general name for the otherwise unspecified relationship between the two terms. The formal logician reminds us that the subject, predicate, and their existence are distinct items, but offers no conceptualization of their relation apart from the misleading use of a conjunction (NB: predication is no more conjunction than it is identity or existence). Existential quantification thus fails as a theory of predication, which

(C) 2013 John Wiley \& Sons Ltd 
is to say that it does not account for the underlying assumptions of the sentences it translates. If we want to understand predication (i.e., if we want a theory of the proposition), we require an explanation of how the general concept in the predicate term relates to the individual existent in the subject term; quantification evades this demand by offering only a negative judgment about predication (viz., it is not identical to identity or existence). How does 'being red' pertain to 'being a rose' in this instance? The formal logician knows only that the same $x$ is both a rose and is red, which is one reason why Quine insisted that the formal logician needs a further ontological theory. Although Hegel's analysis of the positive judgment is in several respects inferior to the quantificational analysis, he is attentive this particular shortcoming of formalistic logics. His concern lies appropriately with the relationship between the two terms. This is why he repeatedly discusses ambiguous 'proposition that the judgment expresses', namely, that 'the individual is the universal'. How are universals predicated of individuals? What is the relationship between an individual rose and its redness? The theory of predication needs to determine just what the predicative copula means when general qualities are ascribed to individual entities.

Hegel begins with the same distinction between subject and predicate, and he argues first for a contextual extension of each term. While he allows that the prima facie form of the sentence is compositional, he sees in the apparently isolated terms distinct contexts that the sentence brings into relation. In other words, Hegel's theory of predication is inferred from the very distinction between the subject and predicate terms, and so not (as Russell imagined) a refusal to recognize that distinction. His analysis grants the independence or givenness of the subject term. ${ }^{37}$ 'The rose' is a given individual object whose identification has been established prior to the utterance, a point that the formalism makes explicit in the term ' $\mathrm{Rx}$ '. We have to know which object is being talked about in order to understand the sentence, and we have to comprehend its status as 'rose'. In this regard the success of variables is very mixed: we do not talk about indefinite objects but rather definite ones. There is no ' $x$ ' that serves as the subject of the sentence, but rather there is a given individual rose. That the use of variables is metaphysically loaded has been recognized by many philosophers of logic, and Quine went as far as to call it 'the essence of ontological idiom' in logic. ${ }^{38}$ The variable comes very close to suggesting that the identity of things is somehow prior to or separate from their having any attributes whatsoever. Variations of this point in metaphysics have arisen under the Kantian notion of a Ding-an-sich as well as, in recent analytic philosophy, the theory of the bare particular. ${ }^{39}$ In any case, the term ' $R x^{\prime}$ is only a confession that a rose has been identified, or more literally that something has been identified as a rose.

The first argument concerning the subject term is a regress from the givenness of the subject: just as the premise of an argument requires a further argument, so does the identification of the individual require previous predications. ${ }^{40}$ For instance, perhaps prior to saying 'the rose is red' it was said or implied that 'the flower in the vase is a rose'. Predication presumes that a previously identified

(C) 2013 John Wiley \& Sons Ltd 
individual object is given, and this identification presupposes further predications. The simple result of this claim is that no predicative sentence can stand alone, but rather each rests on an indefinite sequence of prior predications. ${ }^{41} \mathrm{~A}$ similar argument applies to the predicate term, although this case does not take the form of indefinite regress. The metalogical content of positive judgments, 'the individual is universal', requires not only a previously identified subject, but also a predicative concept with sufficient quantificational status. This conceptual status must be established independently of the judgment in question. In other words, as a general term, the predicate must have an extension considerably wider than the particular assertion under consideration. ${ }^{42}$

Hegel records these points linguistically by distinguishing between sentence and judgment (Satz, Urteil), with the latter of these alone accounting for the contextual specifications of the terms of predication (subject, predicate). A judgment cannot consist only of individual terms, although individual terms could be stated and sandwiched in a sentence around the little word 'is'. Predicative judgments require rather generic predicates like 'red', and the generality of this term also needs some context to account for it. Hegel's example of the sentence-judgment distinction concerns the death of Aristotle: 'Aristotle died at the age of 73 , in the fourth year of the 115th Olympiad.' This would only satisfy the requirements of 'judgment' if:

... under the circumstances that the age of the philosopher or the time of his death was put into doubt, on which grounds the given quantities could be regarded. In this case it would be something general, which would persist even without the particular content the death of Aristotle'. It would either have other content, or even be taken as empty time. $^{43}$

As an independent theoretical claim, Hegel has only asserted something that in the twenty-first century can appear rather plausible: sentential components require broad contextual specifications. ${ }^{44}$ If you ask me what color the rose is you have presumed several things. Some of the background assumptions include: there are many colors, we are familiar with some of the same ones, and roses come in several colors. The predicate can only function as such in light of a broad conceptual background, and the concept 'red' has this independent context prior to our insistence that it also inheres in a given rose. What is more important in this context, however, is the relationship between Hegel's contextualism about conceptual content and the distinction between predication and identity: the contextualism about predication is precisely what distinguishes the predicative judgment from an identity claim (e.g., if 'red' did not have a wide extension there would be no way to distinguish it from other aspects of the rose). ${ }^{45}$ The above analysis concerns only the implications of distinguishing predication from identity. This illustrates the misjudgment in Russell's most famous criticism of Hegel, which is to be discussed in more detail in the last section. Russell claimed that Hegel failed to distinguish between identity and predication, whereas Hegel's entire analysis of predication departs from that

(C) 2013 John Wiley \& Sons Ltd 
distinction. Hegel's thesis is that the distinction between subject and predicate requires that each term be specified by a wider discourse. The compositional account of the sentential components is thus precisely what inspires the argument against the sentence as an independent unit.

\section{Informativeness and the Diversity of Judgments}

In this section I review a few of the later arguments from Hegel's chapter on judgment, in order to explain why Hegel arrives at the conclusion that there is indeed a great diversity of irreducibly valid linguistic forms. The simple point is that subjects and predicates relate in a variety of ways to compose informative sentences, and the diverse relationships do not reduce to a simple calculus. The kinds of sentences that we employ derive from the various relations that hold between subject and predicate. Positive judgments propose a misleadingly simple distinction between the terms, but one that nonetheless conveys information about a previously identified subject: 'what the subject is, is first expressed in the predicate. ${ }^{46}$ The predicate informs the addressee about some aspect of the subject, and the subject term alone does not say much about the individual in question. ${ }^{47}$ Another way of stating this situation is that although the sentence presupposes a prior act of identification, it also presumes that the particular content of the predicate was not included in that identification. The relationship of predication or inherence is such that it provides information about something given. ${ }^{48}$ This requires that the predicate be individuated ('the universal is individual'), just as the subject includes a general quality. ${ }^{49}$ So the judgment not only adds information about a previously identified individual, but also instantiates a general predicate..$^{50}$

Informativeness, as a requirement for successful predication, demands some variance in the relations between the context of the predicate and the givenness of the subject. Hegel's contextualism about the sentence together with this point about informativeness leads to his expansive account of logical form, with its implicit critique of reductive formalism. ${ }^{51}$ In plain terms, since both subjects and the predicates depend on broad and varying contexts, there will be important contextual differences in how these are identified. This is why I claimed in the introduction that logical form depends on the identity conditions of the subject. The main interest of Hegel's theory consists in the detail he lends to his analyses of sentential forms. Since the sentence has so many distinguishable forms, the analysis of these structures reveals a correspondingly diverse ontology. The diverse ontology in turn imposes limits on the applicability of sentential forms, so that the general argument here goes from semantic contextualism to sentential diversity, and from there to the limited application of any given formal analysis (including that in first-order predicate logic).

Hegel distinguishes four kinds of judgment (existential, reflective, necessary, and conceptual), the first two of which introduce a distinction in predicative relations. The former (Das Urteil des Daseins or existential judgment) is charac-

(C) 2013 John Wiley \& Sons Ltd 
terized by the relationship of inherence, whereas the latter (Das Urteil der Reflexion or reflective judgment) concerns the relationship of subsumption. Subsumption includes what contemporary logicians call class membership and class inclusion, although this distinction introduces its own set of metaphysical assumptions. ${ }^{52}$ Species of judgment divide mainly by conceptual or quantificational status of the subject term: existential judgments are assertions about given individuals, reflective judgment involves sentences about classes (the so-called categorical propositions of traditional logic), and the last two categories concern concepts, species, classificatory genii, generic concepts, etc.

The key point that Hegel attempts to establish is that differences in either the identification of the subject term or in the inferential context of the predicate term will change the manner in which the subject and predicate relate to each other. The informativeness of predicates is thus variable given differences in the conceptual and quantificational status of both the subject and predicate terms. This is why there are so many ways of forming sentences: the subject can be a given individual identified in advance, about which is asserted the inherence of a specific general concept (existential judgment). This 'inherence' takes several forms, since general concepts relate to given individuals in several ways. The predicate can be denied of the individual, in which case we have negative judgment. The predicate can belong to a class of predicates, all of which are denied of the subject (infinite judgment). The subject can be specified not merely as a given individual, but rather as a quantified class or set of individuals of a certain type (some, all, etc.). In this case the relation between terms is called 'subsumption', or inclusion. The subsumptive relation distinguishes the predicate and subject terms more sharply than does the relationship of inherence, and this fact has further metaphysical implications (the nominalist will be tempted to stop here).

The more important aspect of so-called reflective judgment is the distinction that arises between class and genus (Gattung), which takes Hegel's argumentfor better or worse-through a detour on the old metaphysical problems of the reality of universals. The examples show a crucial difference in subject and predicate relations, which in the case of the genus admit of further distinctions that Hegel analyzes under the titles 'hypothetical judgment', 'disjunctive judgment', etc. The genus can also function in the predicate term of judgments about individuals, in which case it relates to the subject in a very different manner than does 'red' when predicated of a rose ('Socrates is a man' differs from 'the rose is red'). More important, however, is that the genus can function as a logically singular term in the subject of judgments: "instead of "all humans" we should rather say "humanity". ${ }^{53}$ A passage added to Hegel's Encyclopedia illustrates this distinction by comparing 'all humans are mortal' and 'all humans have earlobes'. ${ }^{54}$ These statements differ logically, as is clear to anyone who presents counterexamples to them. If you point to an apparent human who is immortal, we will either revise our conception of humanity or declare the entity in question not human. If you show me your friend who lacks earlobes, on the other hand, we will simply adjust the quantificational status of our subject term from 'all' to

(C) 2013 John Wiley \& Sons Ltd 
either 'some' or 'most' (NB: the wonderful logic of the English language offers the triple quantifier 'almost all') ${ }^{55}$ 'Humanity' is thus as legitimate a subject of predication as are 'all humans', and this term forms the subject of judgments that have different inferential characteristics than does the quantified sentence (as is evidenced by the counterexample test).

Whatever we make of these issues, or Hegel's positions on them, it suffices to say that the logic of these sentences is not independent of a corresponding ontology. It is also the case that Hegel's metaphysical commitment here is perhaps less rigid than one might fear: to say that 'humanity' is a proper subject of discourse is not yet to commit to a vulgar realism about the species. The problem with species realism, and other contentious metaphysical stances, is that they assert mysterious entities by analogy with the individual existent. The argument here is rather that since the statement about the species has a different logic, it must also have a different ontology. The resultant ontology is neither vague nor supersensible, but it is anti-reductive. Hegel proceeds to elaborate the discursive commitments of a range of legitimate discourses, and he combines these with his general argument against reductively formal logics. The subsequent point in ontology is that reductionism will not work here either. One cannot consistently eliminate 'humanity' by reducing it to 'all humans', since statements about these will differ in important ways. Discussions in ethics, politics, or history concern the former, while perhaps in the natural sciences the

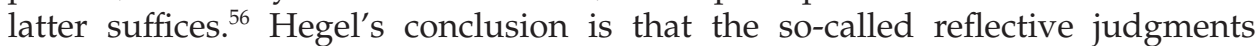
require an ontology distinct from that of the positive (existential) judgment, so that the species (for instance) is precisely not treated as another individual like the human or rose. Another way of reading this point is that the ontological requirements of a statement in ethics or politics differ from those in the natural sciences: an anti-reductive logic requires an anti-reductive ontology, and vice versa.

I wish to consider a second of Hegel's arguments in this vein, while remaining slightly less committal about its validity. He distinguishes some further logical characteristics of genii in his discussions of conceptual judgments (das Urteil des Begriffs) and necessary judgments (das Urteil der Notwendigkeit). What Hegel needs to establish here is that, as above, the logic of these forms of judgment is not reducible to that of the positive judgment. In this case his point is that the predicates often play a role in identifying the subject. Subject terms such as 'humanity' or other normative concepts including 'friend' and 'a wellconstructed house' are simply identified differently than is 'a rose'. Consider the sentence 'a well-constructed house is one that withstands heavy storms'. What Hegel's theory implies is that although one can attempt to formalize it in one of several ways [viz., one may use the conjunction, material inference, or bi-conditional to build something like $(\mathrm{x})(\mathrm{Hx} \cdot \mathrm{Cx})>(\mathrm{y})(\mathrm{Sy}>\mathrm{Wxy} \longrightarrow \mathrm{P}$ predicative differences between that judgment and 'all roses are red ure obscured by the reductive manner of the formalism. ${ }^{57}$ Here exceptions will play a role similar to that played by counterexamples above: although weathering a storm belongs to the concept of a well-constructed house, sometimes well-

(C) 2013 John Wiley \& Sons Ltd 
constructed houses will be destroyed in storms. To give an ethical example, a friend (speaking as a general term) does not betray confidence, but a friend (singular term) who betrays us may still be a friend. These conceptual statements are evaluative, or in Hegel's literal terminology 'apodictic', and conceptual evaluations relate to exceptions differently than do descriptions of individuals or classes. ${ }^{58}$

The reason why no single reductive technique suffices, then, is that the different forms of sentence distinguish subjects and predicates in different manners. One should say, in keeping with both sides of Hegel's hybrid sentential semantics, that the different sentential forms relate the acts of identification in the subject term in different ways to the inferential context of the predicate. Hegel's most far-reaching, and perhaps misleading, thesis here is that predication approaches a species of identity as more of the predicate's inferential content is placed in the subject term: in those cases the predicate cannot be negated without affecting the stated identity of the subject. ${ }^{59}$ This means that the conceptual-hence 'apodictic' - judgments express an adequatio of the subject and predicate terms, one that is perhaps not captured by the English word 'correspondence' in the classical definition of truth. Apodictic and other conceptual judgments have a truth to their form, a truth that the simple positive sentence does not possess. But the formal truth of these sentences consists only in the extent to which the contextualism already suggested by the positive judgment is explicit in the actual assertions. A complex and well-constructed proposition about a rich topic (like 'humanity', 'justice', or 'jazz') approaches the form of argument and theory, and these are only misleadingly expressed by the simple forms of logical connectives.

This point explains some of the mysterious-sounding things that Hegel writes such as 'the unity of the copula is completed in inference ${ }^{\prime 60}$ : it means that a rich predicative copula relates terms in a manner that makes for a complete argument. When we make complex and thoughtful statements about 'the Christian religion' or 'freedom', to mention two of Hegel's pet objects, we specify what we are talking about only within a nuanced discourse. The result is that the sentences have a different form, or relate subject to predicate in a more explicitly argumentative manner. Whereas 'the rose is red' can perhaps serve as a minor premise in a select few inferences, a sentence like 'a well-constructed house is one that can weather heavy storms' already makes an argument. One might say, with Hegel, that the latter conceptual statement expresses an inferential unity that makes explicit the hybrid meaning of the predicative copula. The conceptual judgment is inferential in ways that the positive judgment is not; e.g., withstanding a heavy storm is one of the premises from which one identifies a house as a well-constructed one. In Hegelese, the point is expressed as 'inference is the truth of judgment', which provides a rationale for continuing the analysis by looking at norms of inference rather than just forms of sentences.

Hegel's thesis borders between a fairly modest semantic theory and a stronger ontological version. On the former he is extending what some call semantic sentential contextualism by arguing that just as words have meaning only in

(C) 2013 John Wiley \& Sons Ltd 
sentences, so do sentences have meaning only in arguments. The stronger, and more interesting thesis, however, is that predications are only formally true to the extent that they play a role in argument. The truth of a given predication is not independent of its placement in an argument. ${ }^{61}$ Without explanation of the point here, I wish to add that a similar claim follows from Hegel's analysis of inference: no free-standing arguments are sound. Sentences can only be true when applied, and when the appropriate inferences are drawn from them. Arguments can only be sound when situated in an objective context, which within Hegel's text means that they must be situated in a theory about the real (mechanism, chemism, and teleology). We thereby draw far-ranging metaphilosophical as well as metalogical consequences from this very basic discussion: neither free-standing sentences nor free-standing arguments can comprise a unit of truth in philosophy. Hegel's rejection of the sentence as truth-bearer, then, derives from a number of still-plausible analyses of logical and linguistic forms.

\section{Some Interpretive Aporias of Hegel's Logic}

Although the foregoing comparison between Hegel's theory of predication and the achievements of first-order predicate logic is not entirely novel, the history of criticism and commentary upon Hegel's logic has been much more concerned to discover in his writings examples of inference types rather than analyses of them. Scholars have attempted to cull from his writings either an implicit theory about inferences or illustrations of the gross consequences of ignoring classical first-order logic. In the former case, one asks questions of the sort 'Is Hegel's Logic formalizable?' In the 1970s and 1980s there was a trend along this line, and dozens of articles are now extant in which this question was treated. ${ }^{62}$ One could, for instance, select a portion of Hegelian text and sympathetically abstract a 'logic' from it. What is the abstract structure of Hegel's argument, for instance, that takes us from the study of 'substance' to the study of 'concepts'? Isolating such an argument appeared to accomplish two tasks. First, it translated into a more common logical idiom such Hegelian catchphrases as 'substance is also subject.' Second, it provided a context for extracting from Hegel a contribution to first-order logics. If one could discern in the 'movements' of Hegel's logic just a few basic operations, then Hegel would seem to adhere to the vulgar distinction between form and content. This was the result, for instance, of a specific German literature on the Logic that lasted nearly two decades. ${ }^{63}$ In my view this approach invests too much in the old notion that there is a secret of Hegel—as if his philosophy reduces to a technique-and so that approach does not arrive at a formulation of what Hegel's positions are on articulable issues.

The second horn of the above dilemma is the one taken by the classical analytic philosophers of the tradition of Russell. When we read Hegel's text, they assumed, we should keep the standard logic of post-Fregean traditions in mind and assess his arguments accordingly. Unsurprisingly, Hegel's Logic fares very

(C) 2013 John Wiley \& Sons Ltd 
badly on this kind of analysis. If one insists on reading each of his sentences as a simple predicative assertion, his text would provide a veritable minefield of logical fallacies, and discovering specific examples of these is an easy game. He conflates the various meanings of the copula, draws existential inferences from general statements, and makes other elementary mistakes. Given the presence of these fallacies within Hegelian arguments, together with the obvious correctness of classical logic, there would be no reason to believe that Hegel could have reached any conclusions that are true about whatever exactly it was that he supposed himself to be discussing in the Logic. One locus classicus for this is a passage from a footnote in Russell's Our Knowledge of the External World:

Hegel's argument in this part of his 'Logic' depends throughout upon confusing the 'is' of predication, as in 'Socrates is mortal', with the 'is' of identity, as in 'Socrates is the philosopher who drank the hemlock'. Owing to this confusion, he thinks that 'Socrates' and 'mortal' must be identical. Seeing that they are different, he does not infer, as others would, that there is a mistake somewhere, but that they exhibit 'identityin-difference'. Again, Socrates is particular, 'mortal' is universal. Therefore, he says, since Socrates is mortal, it follows that the particular is the universal - taking the 'is' to be throughout expressive of identity. But to say 'the particular is the universal' is self-contradictory. Again, Hegel does not suspect a mistake but proceeds to synthesize particular and universal in the individual, or concrete universal. This is an example of how, for want of care at the start, vast and imposing systems of philosophy are built upon stupid and trivial confusions, which, but for the almost incredible fact that they are unintentional, one would be tempted to characterize as puns. ${ }^{64}$

The first thing to notice in this passage is that Hegel is supposed to be oblivious to such an obvious distinction as that between predication and identity. If one wanted only to defend Hegel against such lambast, then it would be as easy to select examples of Hegelian texts in which the supposedly conflated concepts are more carefully distinguished. ${ }^{65}$ These could include passages in which Hegel distinguishes the various uses of the copula, such as the amusing discussion in which he proposes that the verbs 'to be' and 'to exist' be used interchangeably. ${ }^{66}$ Secondly, Hegel's argument, as I reconstructed it above, departs from the distinction between identity and predication. Third, what I called the 'metalogical content' of the positive judgment, 'the individual is universal', is not an identity statement. Russell takes Hegel to conflate predication and identity mainly because he does not understand what Hegel means in his second-order, metalogical expressions. 'The individual is the universal' is not some strange metaphysical doctrine that Hegel proposes, but is rather the very assumption that anyone makes when uttering a predicative sentence of the form 'the rose is red'. Hegel's own arguments show in what respects this assumption is inadequate. He does not propose its truth as a free-standing sentence, but rather infers it from the form of the positive judgment.

(c) 2013 John Wiley \& Sons Ltd 
These types of defense, however, possess the shortcoming that they do not exonerate Hegel of any fallacies in the actual execution of his arguments about logic. In other words, it would show that the identity of predication and identity is not an Hegelian doctrine, but not that the Hegelian doctrine, whatever it is, is espoused in a matter that avoids simple conflations of this type. We cannot excuse Hegel's texts from the laws of logic. Although one needs little reason for examining the form of anyone's argument, we have ample reason in Hegel's case. The latter purports to give an extended account of the forms of judgment and inference, and so he should exhibit as much as proclaim logical form. As Hegel would say, the form of his text should be adequate to the content. In this case, a few clear difficulties arise. If the sentence is not alone a sufficient medium of truth, how can this point be conveyed in a book that consists of sentences? If arguments cannot be 'free-standing', how could an essay or volume communicate from one person to another some true content in philosophy? Hegel's critical evaluation of judgment and inference seems to lead him in the direction of aporias of this sort.

It helps this situation to examine a second line of defense in regard to Russell's criticism. One can always appeal to the architectonic of Hegel's text in order to escape claims that he confuses any two ideas. 'Identity', for instance, is a category of the Wesenslogik (the logic of essence and appearance), whereas 'predication' is quite clearly a category of the Begriffslogik, the logic of concepts. Any confusion of identity and predication thus runs counter to the architectonic and organization of Hegel's book. The book distinguishes these notions by placing them in different chapters, which is significant in the case of a book that purports to offer one unbroken argument from beginning to end. Grant this point to Hegel, however, and one might reject every sentence in the book: any given sentence will employ concepts that are removed from the dialectical context in which Hegel justifies them. One way of interpreting the form of Hegel's Logic, then, would be to say that the argument of the text can be true only if the sentences it contains are not. The way of saving this point, of course, is by appealing back to the fact that the sentence is an inappropriate medium of philosophical truth. At the very least, the sentences in Hegel's or any philosophy book have heavily contextual meaning and truth-this last not being adequately construed in the simplest interpretation of 'correspondence'. Some scholars have tried to resolve this problem by claiming that while sentences (for instance) are not truth bearers, they are in some way necessary media for truth. ${ }^{67}$ In simple terms, although you cannot speak a true sentence, you also cannot speak the truth without speaking in sentences.

A second polemic by Russell moves in the reverse direction as the above, aiming at Hegel's apparent reification of the form of predication. Russell abstracts an argument, which he admittedly borrows as much from Bradley as from Hegel:

Now the traditional logic holds that every proposition ascribes a predicate to a subject, and from this it easily follows that there can only be one

(C) 2013 John Wiley \& Sons Ltd 
subject, the Absolute, for if there were two, there proposition that there were two would not ascribe a predicate to either. Thus Hegel's doctrine, that philosophical propositions must be of the for 'The Absolute is such and such ...' depends upon the traditional belief in the universality of the subject-predicate form. ${ }^{68}$

Russell's objection must not be too hastily dismissed by claiming that the absolute is only a category and that Hegel is not a metaphysician. Rather, the precise sense of Hegel's reliance upon the predicative form must be specified. Spinoza indeed treated philosophical propositions as translatable into statements for which the one and only substance could serve as subject. ${ }^{69}$ Hegel would seem to follow Spinoza in some respects, for instance when he says that all the categories of Logic are 'definitions of the Absolute. ${ }^{170}$ It would thus seem that one could say, with a degree of justice, that the absolute is essence, the absolute is substance, and the absolute is the concept. A further metaphysical transgression would be perpetrated by Hegel when he predicates these same categories of 'everything'. Thus we get 'everything is a contradiction', 'everything is a judgment', and 'everything is an inference'. ${ }^{71}$ These statements from Hegel's Encyclopedia Logic would seem to confirm the accusation that he, first, draws metaphysical conclusions from logical premises. Second, Hegel would thus treat all truths as properties of subjects. And lastly, Hegel would be led to a metaphysics in which there is only one known object, the Absolute.

The correct response to these worries is that Hegel's theory of predication declares the simple assertorical statement to be inadequate for philosophical research, and so he cannot have an abstract doctrine of the sort 'the absolute is such and such'. We can thus discard the worry that dominated anglophone discussions of Hegel for the past three decades, viz., that Hegel will be read as proposing a metaphysics of supersensible objects. ${ }^{72}$ Hegel indeed does not propose such a metaphysics, which is to say that he does not assert propositions that he takes to correspond in accurate subject-predicate form to the classical objects of metaphysics: god, the soul, etc. In more contemporary language, sentences that address 'god' or 'Geist' do not have a representational semantics, but are nonetheless important subjects of expressive discourse. This way of putting the point, however, is unnecessary once we have paid sufficient attention to Hegel's analysis of judgment. Hegel explains why the form of the sentence is inadequate, at least in isolation, just like he claims that the ontological 'argument' needs to be 'liberated from the bad form of a proof. ${ }^{173}$ The reason that Hegel is thus not a dogmatic metaphysician is not that he limits himself to conceptual analysis rather than metaphysics, but rather that he shows how the object of philosophy is not an independent given to which general predicates can be ascribed by analogy with 'the rose is red' ${ }^{74}$ This last sentence is simply another way of saying that the predicative sentence is inadequate for philosophy.

Hegel's more well-known doctrine of the 'speculative sentence' expresses this in accordance with a logic of exception. It makes it seem as if there were certain

(c) 2013 John Wiley \& Sons Ltd 
sentences that required a unique analysis, without explanation of why that might be so. This doctrine, however, can be saved in light of the above analysis of judgment. It is not the case that there are certain sentences classified as speculative, as opposed to others. ${ }^{75}$ Rather, the subjects of sentences can be identified and informed by predicates in a variety of ways, and the central propositions of a speculative philosophy are such that they rest as far as possible on the scale away from the likes of 'the rose is red'. The so-called speculative propositions such as 'God is one', however, express a predicative relation akin to that analyzed under the titles 'conceptual judgment' and 'apodictic judgment'. These latter types of sentence only make explicit the hybrid semantics of judgments, so that the speculative proposition as well would seem to merely express something general about propositions: that the predicative form does not express meaning without a broad theoretical context that brings the two terms together.

Kevin J. Harrelson

Department of Philosophy and Religious Studies

Ball State University

USA

kjharrelson@bsu.edu

\section{NOTES}

${ }^{1}$ Earlier versions of this paper were given at the Technische Universität Darmstadt in June 2012, and the Università degli Studi di Padova in December 2012. My thanks go to the participants of those colloquia, especially to Phillip Richter, Jan Müller, Alfred Nordmann, Luca Corti, Michela Bordignon, and Georg Sans. Thanks also to an anonymous reviewer from the European Journal of Philosophy.

${ }^{2}$ All references to the Science of Logic are original translations from the Suhrkamp edition (ed. Moldenhauer and Michel, Suhrkamp 1969) of the Werke, volume 6. All references to the Encyclopedia Logic are to the same edition, volume 8 .

${ }^{3}$ For a straightforward introduction to this topic, see Jere Surber's 'Hegel's Philosophy of Language: The Unwritten Volume' in A Companion to Hegel, ed. Stephen Houlgate and Michael Baur (Wiley-Blackwell 2011), 243-61. Surber offers a more detailed discussion in his 'Hegel's Speculative Sentence' in Hegel-Studien 10 (1975).

${ }^{4}$ A thesis that I take to be similar to Hegel's has recently been defended by Achille Varzi in 'On the Interplay between Logic and Metaphysics' in Linguistic and Philosophical Investigations 8 (2009), 13-36.

${ }^{5}$ Cf. Pirmin Stekeler-Weithofer's review (in European Journal of Philosophy 20:1182-87) of Angelica Nuzzo, ed. Hegel and the Analytic Tradition (Continuum 2009).

${ }^{6}$ For the general interpretive problem here, see James Kreines's 'Hegel's Metaphysics: Changing the Debate' in Philosophy Compass 1:5 (2006): 466-80.

7 See Hegel's insistence that 'Descartes does not speak of a hundert thaler' in the Lectures on the History of Philosophy (Werke 20, 362). I discuss this problem at length in my The Ontological Argument from Descartes to Hegel (JHP Books/Humanity 2009).

${ }^{8}$ In 'Truth, Identity, and Correspondence in Hegel's Critique of Judgment' (in International Philosophical Quarterly 48:4, 2008, pp. 425-36), Ben Levey offers a nice

(C) 2013 John Wiley \& Sons Ltd 
discussion of the basic texts on truth and judgment that distinguish Hegel from metaphysicians before Kant. Most of the texts appear either in the Phenomenology or the Encyclopedia, whereas below I deal almost exclusively with the larger Logic.

9 'Ontological Remarks on the Propositional Calculus' in Mind 43 (1934); reprinted in The Ways of Paradox (Revised Edition, 1976), 265-271.

${ }^{10}$ See the essay 'On Carnap's Views on Ontology' in Ways of Paradox 203-11.

${ }^{11}$ For a very recent contribution to the debate on propositionalism, see Sean Crawford's 'Propositional or nonpropositional attitudes' in Philosophical Studies (April 2013 DOI 10.1007/s11098-013-0126-6). For a classic discussion see Frege and the Logic of Sense and Reference by Kevin C Klement (Routledge 2002).

${ }^{12}$ I refer here to the progressive analysis of forms in the chapter on Judgment (Werke $6,301-51)$, much of which is discussed in sections 2 and 3 below.

${ }^{13}$ See the discussion of Russell below. For some texts on this topic by Hegel see Werke $6,312 \mathrm{ff}$.

${ }^{14}$ This point is well explained in the chapter on Concepts, which precedes the chapter on Judgment. See especially Werke 6, 297 where Hegel discusses the examples of 'Leben, Geist, (und) Gott.'

${ }^{15}$ I borrow this expression from Graham Priest's 'On Alternative Geometries, Arithmetics, and Logics; A Tribute to Łukasiewicz' in Studia Logica: An International Journal for Symbolic Logic, Vol. 74, no. 3 (Aug. 2003), 441-68.

${ }^{16}$ See especially Werke 6, 266-68 and my analysis of these texts below.

17 Werke 18, 125.

${ }^{18}$ Zeller was especially effective in portraying Hegel's Logic as outside the boundaries of the classical inquiry, see his 'Ueber Bedeutung und Aufgabe der Erkenntnistheorie' appears, among other places, in Vortraege und Abhandlungen (Leipzig 1887) 479-526. Compare Trendelenburg's Die logische Frage in Hegels System (Leipzip 1843).

${ }^{19}$ Encyclopedia Logic \#163 Zusatz, (Werke 8, 312).

${ }^{20}$ Our Knowledge of the External World (Open Court 1914; reprint Routledge 1993), p. 47; Russell was responding to Henry Macran's publication of Doctrine of Formal Logic (Oxford, Clarendon 1911).

${ }^{21}$ Compare Pirmin Stekeler-Weithofer's frequent arguments to this point, such as in 'Generisches Wissen in kategorialen Inferenzstrukturen: Zur Metaphysik des Begrifflichen' in. In: Volker Munz, Klaus Puhl und Joseph Wang (Eds.): Language and World Part Two: Signs, Minds and Actions. Proceedings of the 32th International Ludwig Wittgenstein-Symposium in Kirchberg am Wechsel, Ontos Verlag, Frankfurt/M. 2009, S. 191-215.

${ }^{22} \mathrm{NB}$ : even if formal logics were not often applied to various areas of philosophy, the metaphysical implications of such techniques would still warrant some investigation.

${ }^{23}$ Russell sometimes expressed uncertainty on this issue, and Quine thought logic need only cover the natural sciences.

${ }^{24}$ In the introduction to the Begriffslogik he writes: 'The laws of logic by themselves ... are commonly restricted, apart from the law of contradiction, to some meager propositions concerning the conversion of judgments and the form of syllogisms.' Miller's translation 594; Werke 6, 268.

${ }^{25}$ (Werke 6, 266) Hegel not only modifies Kant's sentence structure, but combines clauses that in Kant are separated by a few hundred words $\mathrm{KrV}$ B 83-84; In another passage Kant supplies an argument for formalism by a reductio from the concept of a material logic. The idea of a general criterion of material truth, Kant claims, is selfcontradictory: 'we cannot seek a criterion for the truth of the material, because that is self-contradictory.'

(C) 2013 John Wiley \& Sons Ltd 
${ }^{26}$ On this point, I am grateful to have listened to Angleica Nuzzo's lecture on 'General logic, transcendental logic, speculative logic' at the University of Pavia (Sistema e logica in Hegel 200 anni della Scienza della logica), December 13, 2012.

${ }^{27}$ Werke 6, 267: 'a content, of the sort [Kant mentions] without its predicates is a blind material, a something without an essence' (... ohne den Begriff ist ein Begriffsloses, somit ein Wesensloses).

${ }^{28}$ Werke 6, 267: 'Leaving all mention of the content aside, which (content) causes the confusion-in which formalisms enters and which forces it to say the opposite of what it intends as soon as it endeavors upon any explanation ...'.

${ }^{29}$ See the Introduction to Robert Pippin's, Kant's Theory of Form (Yale 1982).

${ }^{30}$ Cf. Terry Pinkard's 'The successor to metaphysics' in Monist: An International Quarterly Journal of General Philosophical Inquiry, 74(3), 295-328. 34 p. July 1991.

${ }^{31}$ Werke 6, 267.

32 Ibid.

${ }^{33}$ For a straightforward introduction to this topic, see Lorenz B. Puntel's 'Truth, Sentential Non-compositionality, and Ontology' in Synthese, 124(1/2) 2001, pp. 22159.

${ }^{34}$ The very earliest essays on this topic, such as S. Waterlow's 'Some Philosophical Implications of Mr. Bertrand Russell's Logical Theory of Mathematics' (in Proceedings of the Aristotelian Society 10, 1909-10, 132-88) already propose the naïve interpretation of 'existence' that I criticize below.

${ }^{35}$ Gilbert Ryle offers a very common interpretation of this thesis in his polemic against Collingwood in Mind, New Series, Vol. 44, no. 174 (Apr., 1935), pp. 137-51.

${ }^{36}$ Logic textbooks are littered with mistakes on this point.

${ }^{37}$ See Werke 6, 309.

${ }^{38}$ Quine opened an excellent 1972 lecture on 'The Variable' with the following words: 'The variable qua variable, the variable an und fur sich and par excellence, is the bindable objectual variable. It is the essence of ontological idiom, the essence of the referential idiom.' Ways of Paradox, p. 272.

${ }^{39}$ Compare what Hegel writes in his chapter on 'The Thing', especially in relation to existence (Werke 8, 129-33).

${ }^{40}$ This argument is fairly familiar from many Hegelian contexts.

${ }^{41}$ Unless, of course, there are some original sentences that merely record perceptual episodes.

42 (Werke 6, 316) This is a point at which we could put Hegel on one side of a divide along with Frege, whereas others (e.g., Santayana) stand on the other side.

${ }^{43}$ Werke 6, 305.

${ }^{44}$ Eighteenth-century versions of the point include the principle of thoroughgoing determination as this appears in Kant and underlay the metaphysics of the Wolffian school.

${ }^{45}$ Werke 6, 314

${ }^{46}$ Werke 6, 303; Cf. Encyclopedia Logic. \#169 (Werke 8, 320).

${ }^{47}$ See Werke 6, 303. This shortcoming of the subject term reaches its extreme in the name, which refers without describing. Hegel's frequent discussions of theology are also important here, since in most traditional proofs of the existence of God, 'God' functions as a name rather than a properly philosophical concept. See, for instance the introduction to 'Objectivity' (Werke 6, 403) and Encyclopedia Logic. \#169 (Werke 8, 320).

${ }^{48}$ The converse criterion for the predicate terms ('the universal is individual') is just as simple: the redness can be individuated. The judgment 'the rose is red' does not speak

(C) 2013 John Wiley \& Sons Ltd 
of redness in general, but of a particular redness: 'the rose smells pleasant; the pleasant smell is not any pleasant smell, but the pleasant smell of the rose' (Werke 6, 314).

${ }^{49}$ Ibid.

${ }^{50}$ The theory of predication must address both the identification of individuals and the ground covered by the Platonic theory of methexis, (participation, Teilnahme). For an application of this problem to logic and semantics, see Stekeler-Weithofer's 'The Way of Truth: Parmenides seminal reflections on logic, semantics, and the methodology of science' in Audiator vox sapientiae: studia grammatica Bd. 52 (Akademie Verlag, Berlin 2001).

${ }^{51}$ See Werke 6, 266.

${ }^{52}$ This distinction is, of course, metaphysically loaded.

${ }^{53}$ To defend this point has been the burden of Stekeler-Weiterhofer's most recent work. See his 'Zur Logik des Aber' in Allgemeine Zeitschrift für Philosophie 34(1), 24-59, 2009.

${ }^{54}$ See Enz. \#175 Zusatz $(8,327)$; For a discussion of this example see Robert Stern's Hegelian Metaphysics, p. $155 \mathrm{ff}$.

${ }_{55}$ Werke 6, 332.

${ }^{56}$ An interesting application of semantics to historical language appears in Section IV of Frank Ankersmit's 'Rorty and History' (in New Literary History 39-1, 2008, 78-100).

${ }^{57}$ Thanks to Juli Thorson for a discussion of this example.

${ }^{58}$ I take this to be an application of Stekeler-Weithofer's analysis of the logic of 'but' in 'Zur Logik des Aber'.

${ }^{59}$ See especially Werke 6, 334 .

${ }^{60}$ Werke 6309, 351.

${ }^{61}$ Pirmin Stekeler-Weithofer expresses a similar point when he writes that 'no free-standing sentences are true' (Hegel's Analytic Pragmatism, unpublished manuscript, p. 173).

${ }^{62}$ For a review of this literature see Walter Zimmerli's, 'Is Hegel's Logic a logic?' in William Desmond's Hegel and his Critics (SUNY Press 1989), 191-202.

${ }^{63}$ The paradigm instance of this trend is Dieter Henrich's 'Hegels Grundoperation' in Der Idealismus und seiner Gegenwart (Meiner 1976) 208-30.

${ }^{64}$ Our Knowledge of the External World, 39-40; See Katharaina Dulckeit's excellent discussion of this passage in 'Hegel's Revenge on Russell' (in Desmond 111-34).

${ }^{65}$ See especially Werke 6, 316ff.

${ }^{66}$ Werke 6, 407.

${ }^{67}$ See Chong-Fuk Lau's Hegels Urteilskritik (Munich, Fink Verlag 2002). A detailed English-language discussion of this work by Ionnis D. Trisokkas appears in The Bulletin for the Hegel Society of Great Britain 57-58, 2008, pp. 154-72.

${ }^{68}$ Our Knowledge of the External World, 48.

${ }^{69}$ See the many uses of 'God insofar as' to refer to a particular modification of God in Ethics II P10 and ff.

${ }^{70}$ Encyclopedia Logic \#85 ff. (Werke 8, 182ff).

${ }^{71}$ This manner of expression is more representative of the Encyclopedia than the larger Logic. See \#167 (Werke 8, 318).

${ }^{72}$ On this topic see the Introduction to Stern's Hegelian Metaphysics, and Kreines' review thereof in Bulletin of the Hegel Society of Great Britain, 65/66, pp. 117-21.

${ }^{73}$ Werke 6, 402.

${ }^{74}$ Cf. Encyclopedia Logic \#85 (Werke 8, 182).

${ }^{75}$ Cf. Lau.

(ㄷ) 2013 John Wiley \& Sons Ltd 